\title{
Phosphoinositide Metabolism and Prostacyclin Formation in Retinal Microvascular Endothelium: Stimulation by Adenine Nucleotides
}

\author{
PATRICIA L. ROBERTSON*, DIANE AR and GARY W. GOLDSTEIN ${ }^{*}$ \\ Departments of Pediatrics and Neurology, University of Michigan, Ann Arbor, MI 48109, U.S.A. and \\ 'The Kennedy Institute and Departments of Pediatrics and Neurology, Johns Hopkins University,
} Baltimore, MD 21205, U.S.A.

(Received 13 February 1989 and accepted in revised form 27 June 1989)

\begin{abstract}
Phosphoinositide lipid metabolism and prostacyclin production are implicated in endothelium dependent vascular relaxation in large blood vessels. To determine if these biochemical pathways might be involved in the regulation of microvascular tone in the retina, we measured the formation of 6-keto-prostaglandin$\mathrm{F}_{1 x}$, the stable end product of prostacyclin, and inositol phosphates from ${ }^{3} \mathrm{H}$-labeled phosphoinositide lipids, in endothelial cells prepared from bovine retinal microvessels and maintained in long-term culture. We found that adenosine 5'-triphosphate and adenosine 5'-diphosphate both stimulated a dose-dependent accumulation of inositol phosphates and of 6-keto-prostaglandin- $F_{1 \alpha}$ in these cells. The agonist speciticity of the responses, with stimulation by adenosine $5^{\prime}$-triphosphate and adenosine $5^{\prime}$-diphosphate, and inactivity of adenosine $5^{\prime}$-monophosphate and adenosine, suggest that they are mediated through $\mathrm{P}_{2}$ purinergic receptors. The similar early time courses of 6-keto-prostaglandin- $F_{1 \alpha}$ and inositol triphosphate production support the hypothesis that prostacyclin formation could result from the mobilization of intracellular calcium by inositol triphosphate, which activates phospholipase $A$, and thereby releases arachidonic acid to form prostacyclin. These findings point to a role for these cells in the regulation of normal retinal vascular tone. Because phosphoinusitide lipid metabolism is altered in diabetes, dysfunction of these biochemical pathways in retinal endothelium could underlie the pathophysiology of diabetic retinopathy.

Key words: retinal endothelium; phosphoinositide lipid metabolism; prostacyclin; ATP; purinergic receptor.
\end{abstract}

\section{Introduction}

Retinal blood vessels have the capacity for autoregulation that maintains an almost constant rate of blood flow to the retina in the presence of fluctuations in intraocular or arterial pressure (Isacopoulos, 1977). Disturbances in this process may underlie retinal pathology in disease states such as diabetes. The biochemical mechanisms that control retinal vascular autoregulation, however, are not clear, though involvement of local or systemic humoral factors seems likely since these vessels lack autonomic innervation and respond to vasoconstrictors such as angiotensin II and norepinephrine (Dollery, Hill and Hodge, 1963; Rockwood et al., 1987).

Blood vessel smooth muscle contraction or relaxation is the final common pathway in the modulation of blood flow. In the vasculature of other organs, endothelial cells play an important role in this process. After stimulation of specific cellular receptors for several neurohumoral substances including acetylcholine, bradykinin, and adenosine 5'-triphosphate (ATP), endothelial cells secrete vasoactive factors that induce smooth muscle relaxation (Furchgott and Zawadzki, 1980; Chand and Altura, 1981; Martin et al., 1985). How these vasodilator substances are

* For correspondence at: University of Michigan Medical School, Section of Pediatric Neurology, R6060 Kresge II. Box 0570, Ann Arbor, MI 48109-()570), U.S.A. synthesized and regulated is not completely understood. However, the involvement of membrane phosphoinositide (PI) lipids is implicated in the process, by the production of prostacyclin and the metabolism of PI lipids to inositol phosphates, a second messenger pathway for cellular signal transduction (Derian and Moskowitz, 1986; Forsberg et al., 1987; Pirotton et al., 1987).

Endothelial cells in the retinal microvasculature are sealed together by continuous tight junctions forming the blood-retinal barrier (Cunha-Vaz, 1976). Thus, the endothelial plasma membrane in retina presents the first, and sometimes exclusive, site of interaction between blood-borne humoral factors and the retinal vasculature. Therefore, it was important to study how potentially vasoactive factors influence retinal endothelium. Endothelial cells isolated from retinal microvessels and grown in culture provide a convenient tool to study responses of these cells, isolated from other types of microvascular cells. Hcre, we describe a method for the long-term culture of bovine retinal microvascular endothelium, and the ability of selected agonists to stimulate hydrolysis of membrane PI lipids and production of prostacyclin. We found that ATP and adenosine 5'-diphosphate (ADP), nucleotides which probably act through $\mathrm{P}_{2}$ purinergic receptors on retinal cells, stimulated the formation of prostacyclin and the metabolism of PI lipids, with formation of the second messenger, inositol triphosphate $\left(\mathrm{IP}_{3}\right)$. 
To our knowledge, this is the first demonstration of PI turnover and prostacyclin formation by retinal endothelial cells and points to a role for these cells in the regulation of retinal microvascular function.

\section{Materials and Methods}

\section{Preparation and Culture of Bovine Microvascular Endothelium}

Ten bovine eyes were obtained from a local abattoir and transported to the laboratory on ice. After being rinsed with $70 \%$ ethanol, the globes were incised and the retinas removed. They were washed in three changes of ice cold M-199 medium (Gibco). and placed, two at a time, on a $180-\mu \mathrm{m}$ nylon mesh (Tetko Inc.), secured with a rubber band over a $90-\mathrm{mm}$ buchner funnel, and washed extensively by flushing with cold medium to remove fragments of pigment epithelium. The tissue was then suspended in 10 volumes of M-199 and homogenized in a 55-ml teflon/glass Potter Elvehjem-type tissue grinder $(0.25 \mathrm{~mm}$ clearance) at $400 \mathrm{rpm}$. The homogenate was centrifuged at $1000 \mathrm{~g}$ for $5 \mathrm{~min}$. The pellet was resuspended in M-199 and filtered through 118- $\mu \mathrm{m}$ nylon mesh with more medium. Finally, the microvascular segments were collected on $53-\mu \mathrm{m}$ nylon mesh and rinsed into another tube. The suspension was centrifuged at $200 \mathrm{~g}$ for $5 \mathrm{~min}$ and the pellet resuspended in $10 \mathrm{ml}$ of collagenase/dispase (Boehringer-Mannheim $-2 \mathrm{mg} \mathrm{ml}^{-1}$ in M-199/0.5\% bovine serum albumin). The capillaries were digested at $37^{\circ} \mathrm{C}$ with gentle agitation on a gyratory shaker for $60 \mathrm{~min}$ at $100 \mathrm{rpm}$. Each $5 \mathrm{ml}$ of the enzyme digest was layered over $5 \mathrm{ml}$ of Ficol-Paque (in a $15 \mathrm{ml}$ tube), and centrifuged at $1250 \mathrm{~g}$ for $20 \mathrm{~min}$ in a swinging bucket rotor. The upper layer was discarded and the interface band of cells (approximately $1 \mathrm{ml}$ containing predominantly microvascular segments) transferred and resuspended in $10 \mathrm{ml}$ of medium. The lower layer was discarded and the pellet (containing predominantly single endothelial cells) resuspended in $10 \mathrm{ml}$ of medium. The suspensions were recentrifuged at $200 \mathrm{~g}$ for $5 \mathrm{~min}$ and the pellets resuspended in complete medium which was minimal essential medium (MEM) with D-valine (Gibco) supplemented with $20 \%$ fetal bovine serum. One \% MEM non-essential amino acids, $1 \%$ MEM-vitamins, $100 \mathrm{U} \mathrm{ml}^{-1}$ penicillin/streptomycin, endothelial cell growth supplement, $50 \mu \mathrm{g} \mathrm{ml}^{-1}$ (Collaborative Research, Inc.). and heparin, $16 \mathrm{U} \mathrm{ml}^{-1}$ (Sigma). The cells from the interface and pellet were plated in three and two 25- $\mathrm{mm}^{2}$ flasks, respectively, coated with $2 \%$ gelatin. Cultures from both areas of the Ficol-Paque gradient yielded cultures which were endothelial in appearance by phase contrast microscopy. The endothelial origin of the cells was confirmed by their expression of Factor VIII antigen and by their increased uptake of acetylated low density lipoprotein (LDL), the standard markers for endothelial cells in culture. Factor VIII antigen detection was performed using rabbit anti-human factor VIII (Behring Diagnostics) at a $1: 10$ dilution and fluorescein conjugated goat anti-rabbit IgG (Cappel) at a 1:20 dilution (Jaffe, Hoyer and Nachman. 1973). Uptake of LDL (Fig. 1) was demonstrated with the fluorescent probe $1.1^{1}$ dioctadecyl-1-3, $3,3^{1} 3^{1}$-tetramethyl-indo-carbocyanine percholate (Biomedical Technologies, Inc.. Stoughton. MA) (Voyta et al., 1984).

Cells were subcultured by trypsinization with trypsin/ EDTA for $5 \mathrm{~min}$ at $37^{\circ} \mathrm{C}$. The trypsinization was

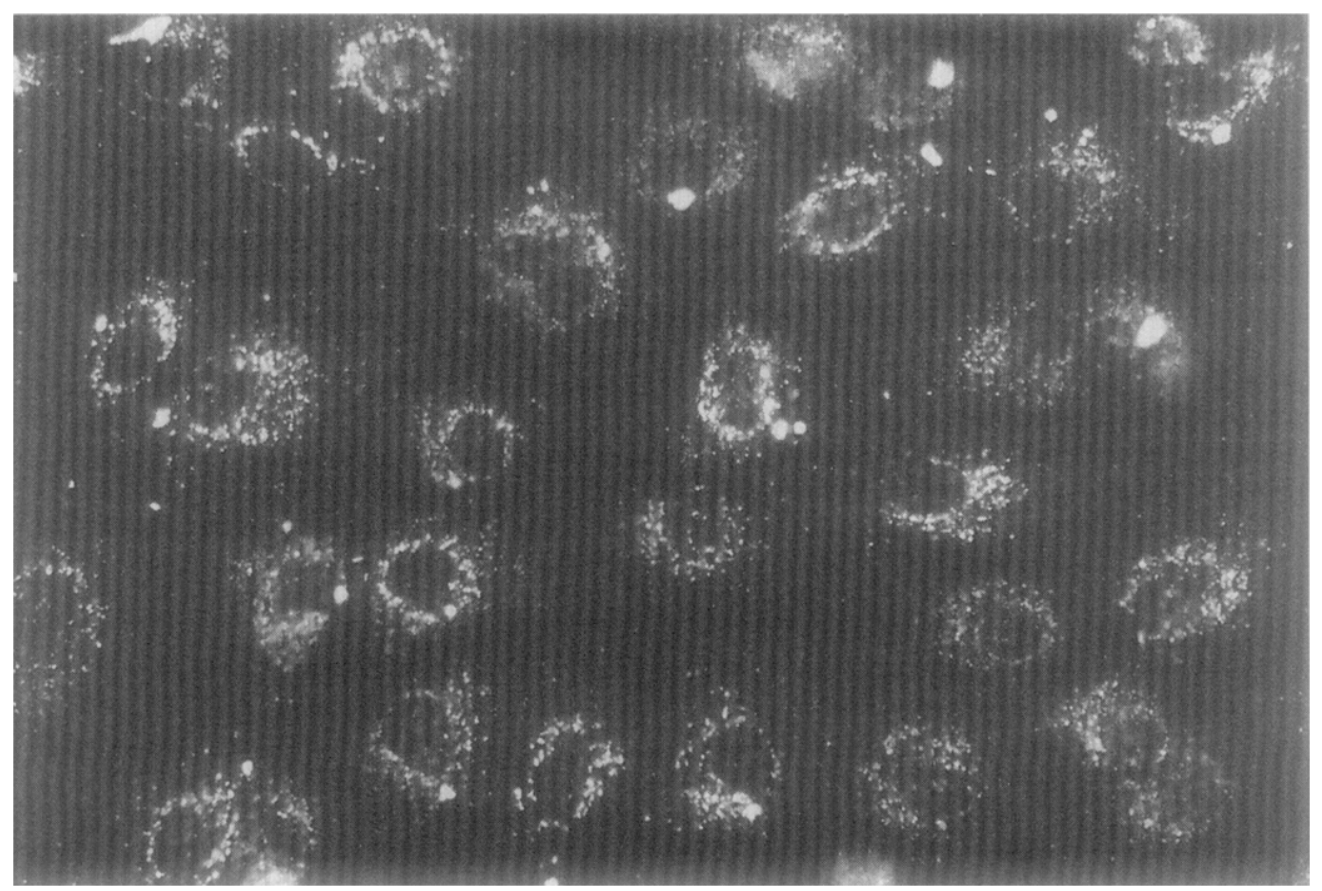

FIG. 1. Light micrograph of subconfluent bovine retinal endothelial cells fluorescently labeled with acetylated LDL $(\times 400)$. 
stopped by the addition of $10 \%$ fetal bovine serum, the cells were centrifuged and resuspended in complete medium at a 1:5 split ratio and passed to six well multiplates (Costar). The cells were used between passages 3 and 8 during which they retained characteristic morphology and marker expression.

\section{Measurement of Inositol Phosphate Formation}

Measurement of individual and total inositol phosphates was performed using a modification of previously described methods (Berridge et al., 1983). Confluent cultures of bovine retinal endothelium at passages between 3 and 8 , and grown in six well multiplates (Costar), were prelabeled for $24 \mathrm{hr}$ with $10 \mu \mathrm{Ci} \mathrm{ml}{ }^{-1}$ myo-[2- $\left.{ }^{3} \mathrm{H}\right]$ inositol $\left(15 \mathrm{Ci} \mathrm{mM}^{-1}\right.$, ARC Inc., St Louis, MO) in $1 \mathrm{ml}$ of $5 \%$ fetal bovine serum $/ 5 \%$ calf serum in MEM with D-valine. After removal of the labeling medium, the cells were stimulated with various concentrations of agonists, [(ATP, ADP, AMP, adenosine, CTP, GTP, UTP, bradykinin (Sigma), calcium ionophore A23187-(Calbiochem, LaJolla, CA)] in $1 \mathrm{ml}$ per well MEM-D-valine containing $10 \mathrm{mM}$ lithium chloride, for various lengths of time. The incubations were terminated by the addition of $1 \mathrm{ml}$ of $10 \%$ ice-cold trichloroacetic acid and allowed to sit at room temperature for $30 \mathrm{~min}$. The cells were scraped from the wells, the suspension centrifuged, and the deproteinized supernatant washed six times, each with $3 \mathrm{ml}$ of water saturated ether, and neutralized with $1 \mathrm{M} \mathrm{KHCO}_{3}$. For determination of total inositol phosphates (IP), the neutralized supernatant was added to $1 \mathrm{ml}$ of a $50 \%$ slurry $(\mathrm{w} / \mathrm{w}$ ) of Dowex AG $1-8 \times$ resin (formate form, BioRad, Richmond, CA), which was washed free of labeled myo-inositol with $5 \mathrm{~mm}$ myoinositol $(6 \times 5 \mathrm{ml})$ and eluted with $1 \mathrm{ml}$ of $1 \mathrm{M}$ ammonium formate $/ 0 \cdot 1 \mathrm{M}$ formic acid. The radioactivity in a $0.8 \mathrm{ml}$ aliquot of the eluate was quantitated by liquid scintillation counting.

For determination of the individual inositol phosphates, inositol triphosphate $\left(\mathrm{IP}_{3}\right)$, inositol diphosphate $\left(\mathrm{IP}_{2}\right)$, and inositol monophosphate $\left(\mathrm{IP}_{1}\right)$, the TCA deproteinized supernatant, washed and neutralized, was applied to a column containing $1 \mathrm{ml}$ of a $50 \%$ slurry of the Dowex resin. $\mathrm{IP}_{1}, \mathrm{IP}_{2}$ and $\mathrm{IP}_{3}$ were sequentially eluted with $3 \times 2 \mathrm{ml}$ of $0.2 \mathrm{M} \mathrm{Na}$ formate/ $0 \cdot 1 \mathrm{M}$ formic acid. $0 \cdot 4 \mathrm{M} \mathrm{Na}$ formate $/ 0 \cdot 1 \mathrm{M}$ formic acid, and $1.0 \mathrm{M} \mathrm{Na}$ formate $/ 0.1 \mathrm{M}$ formic acid, respectively. Radioactivity in the eluates was then quantitated by liquid scintillation counting.

To determine the production of prostacyclin by retinal endothelium, formation of its stable degradation product. 6-keto prostaglandin $\mathrm{F}_{1 x}\left(6-\mathrm{k}-\mathrm{PGF}_{1 \alpha}\right)$, was measured. Confluent cultures of cells in six well multiplates were stimulated by the various agonists for various times at $37^{\circ} \mathrm{C}$. After the incubation, medium containing $6-\mathrm{k}-\mathrm{PGF}_{1 \alpha}$ produced and released by the cells, was immediately frozen at $-70^{\circ} \mathrm{C}$ and the levels determined using a radioimmunoassay kit from New
England Nuclear. The antibodies in these assays have high affinity for 6-k-PGF ${ }_{1 \alpha}$ and low cross reactivity with a number of related prostaglandins. Separation of the antibody-antigen complexes from the free antigen was achieved by absorption of the free ${ }^{3} \mathrm{H}$ tracer onto activated charcoal. Proteins in individual wells were performed by the BioRad method.

\section{Results}

We found that ATP stimulated rapid production of $6-\mathrm{k}-\mathrm{PGF}_{1 x}$, the stable end product of prostacyclin, in cultured retinal endothelial cells. ATP $(10 \mu \mathrm{M})$ stimulated activity which was $185 \%$ of basal, after a $10-\mathrm{sec}$ exposure, and which increased to $600 \%$ of basal after $20 \mathrm{~min}$ (Fig. 2). A similar time course of $6-\mathrm{k}-\mathrm{PGF}_{1 \alpha}$ production was observed after stimulation by $10 \mu \mathrm{M}$ ADP (data not shown). The production of 6-k-PGF stimulated by ATP for $10 \mathrm{~min}$, was concentration dependent between $0 \cdot 1 \mu \mathrm{M}$ and $1000 \mu \mathrm{M}$ ATP (Fig. 3).

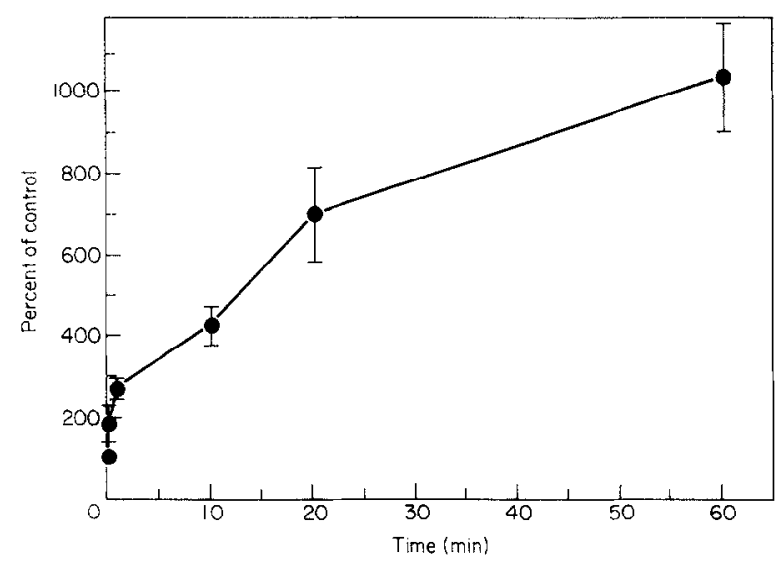

Fig. 2. Time course of ATP induced 6-k-PGF cumulation in bovine retinal endothelial cells. Confluent cultures of cells were stimulated with $10 \mu \mathrm{M}$ ATP for the times indicated. Results are expressed as the percent of control performed in the absence of ATP. Control level was $2 \cdot 3 \pm 0.3 \mathrm{pg} 6-\mathrm{k}-\mathrm{PGF}_{1 \alpha}$ per $\mu \mathrm{g}$ protein. Values are the mean of three determinations \pm S.E.M.

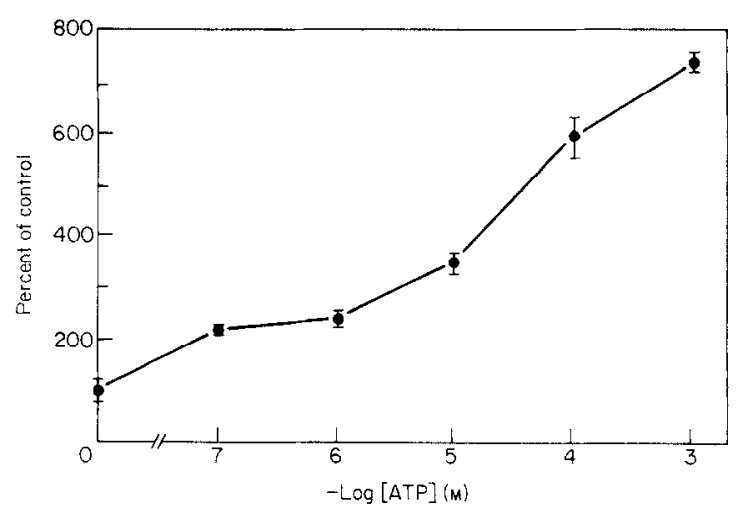

FIG. 3. Concentration dependence of ATP induced 6-k$\mathrm{PGF}_{1 x}$ formation in retinal endothelial cells. Confluent cultures of cells were stimulated with various concentrations of ATP for $10 \mathrm{~min}$ at $37^{\circ} \mathrm{C}$. Results are expressed as percent of controls performed in the absence of nucleotide. Control level was $1 \cdot 1 \pm 0 \cdot 2 \mathrm{pg} 6-\mathrm{k}-\mathrm{PGF}_{1, \alpha}$ per $\mu$ g protein. Values are the mean of three determinations \pm S.E.M. 

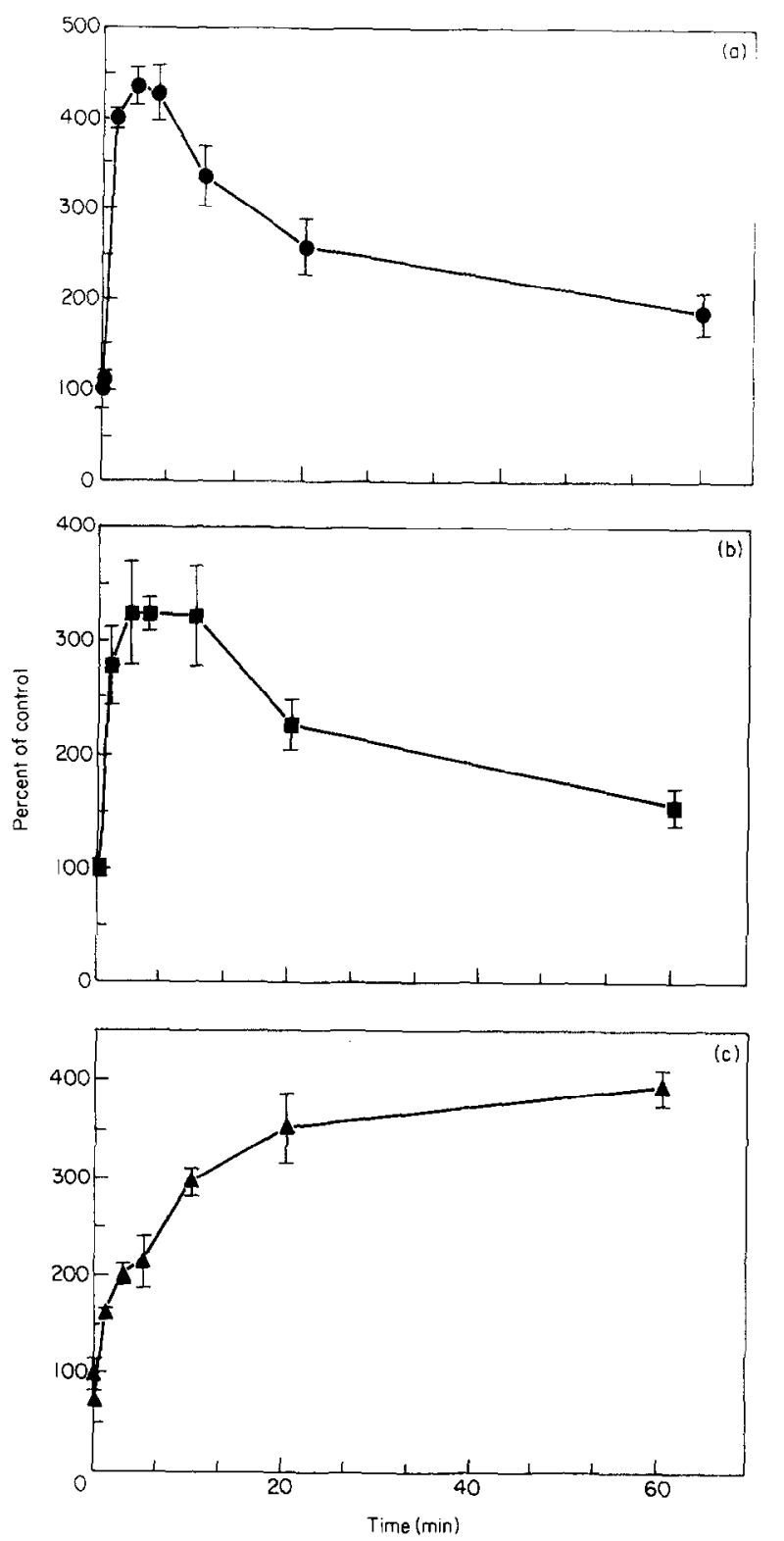

FIG. 4. Time course of ATP stimulated individual inositol phosphate formation in retinal endothelial cells. Confluent cultures of cells prelabeled with myo- $\left[2-{ }^{3} \mathrm{H}\right]$ inositol were stimulated with $10 \mu \mathrm{M} \mathrm{ATP}$ at $37^{\circ} \mathrm{C}$ for the times indicated, and the levels of $\mathrm{IP}_{3}$ (panel a), $\mathrm{IP}_{2}$ (panel $\mathrm{b}$ ), and $\mathrm{IP}_{1}$ (panel c) measured. The results are expressed as the percent of controls performed in the absence of ATP. Control level of $\mathrm{IP}_{3}$ was $2 \cdot 1 \pm 0.4 \mathrm{cpm}$, of $\mathrm{IP}_{2}$ was $0.7 \pm 0 \cdot 1 \mathrm{cpm}$, and of $\mathrm{IP}_{1}$ was $11.4 \pm 0.5 \mathrm{cpm}{ }^{3} \mathrm{H}$ incorporated into inositol phosphates per $\mu \mathrm{g}$ protein. Values are the mean of three determinations \pm S.E.M.

It is possible that $6-\mathrm{k}-\mathrm{PGF}_{1 \alpha}$ production is mediated by an elevation of intracellular $\mathrm{Ca}^{2+}$ through the formation of $\mathrm{IP}_{3}$, the putative second messenger that raises the level of intracellular calcium. Therefore, ATP was also tested for its capacity to stimulate the production of inositol phosphates from ${ }^{3} \mathrm{H}$-labeled PI lipids in retinal endothelial cells. Lithium chloride (10 mM) was included in the incubation medium to inhibit $\mathrm{IP}_{1}$-phosphatase, which prevents degradation of $\mathrm{IP}_{1}$, allowing the measurement of its accumulation at later time points. Figure 4 shows the time course of

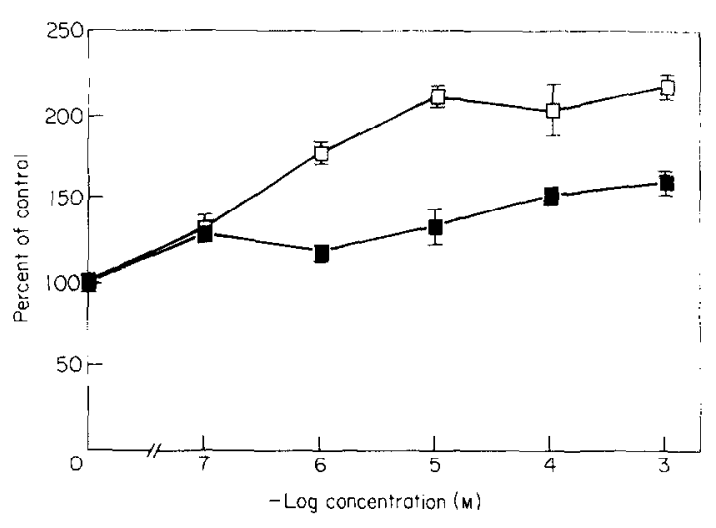

FIG. 5. Concentration dependence of ATP and ADP induced total inositol phosphate formation in retinal endothelial cells. Cells were grown to confluence, prelabeled with myo- $\left[2-{ }^{3} \mathrm{H}\right]$ inositol, and stimulated with various concentrations of ATP and ADP for $10 \mathrm{~min}$. Results are expressed as percent of controls performed in the absence of nucleotide. Control level of IP was $18.9 \pm 0.8 \mathrm{cpm}{ }^{3} \mathrm{H}$ incorporated into inositol phosphates per $\mu \mathrm{g}$ protein. Values are the mean of three determinations \pm S.E.M. .

ATP stimulation of $\mathrm{IP}_{1}, \mathrm{IP}_{2}$ and $\mathrm{IP}_{3}$. After $10 \mathrm{sec}$ exposure to $10 \mu \mathrm{M}$ ATP, $\mathrm{IP}_{3}$ was $112 \%$ of control, rose to $400 \%$ of control by $1 \mathrm{~min}$, peaked at $435 \%$ of control at $3 \mathrm{~min}$, and began to decrease at $10 \mathrm{~min}$. $\mathrm{IP}_{2}$ formation followed a similar time course. $\mathrm{IP}_{1}$ began to rise by $1 \mathrm{~min}$ but did not peak until $20 \mathrm{~min}$, at $352 \%$ of control, where it remained constant until $60 \mathrm{~min}$.

The stimulation of total IP production by ATP and ADP was also concentration dependent (Fig. 5). After a 10-min exposure in the presence of $10 \mathrm{~mm}$ lithium, both ATP and ADP stimulated production of total IP above control, at concentrations between $0 \cdot 1 \mu \mathrm{M}$ and $1000 \mu \mathrm{M}$. Production of IP increased at concentrations between $0 \cdot 1 \mu \mathrm{M}$ and $10 \mu \mathrm{M}$ ATP and plateaued between $10 \mu \mathrm{M}$ and $1000 \mu \mathrm{M}$ ATP. ADP stimulated production of increasing levels of IP at concentrations between $0.1 \mu \mathrm{M}$ and $100 \mu \mathrm{M}$, with levels reaching a plateau between 100 and $1000 \mu \mathrm{M}$ ADP. The maximum degree of stimulation of total IP accumulation by ATP and ADP did vary between experiments with different batches of cells, with the range of maximal stimulation by ATP between $190 \%$ and $530 \%$ of control (data not shown). However, in each experiment, stimulation by ATP was consistently greater than that by ADP in proportions similar to that shown in Fig. 5.

Since ADP and ATP in other systems appear to mediate their cellular effects via $P_{2}$ purinergic receptors, to determine if this was also the case in retinal endothelial cells, we measured total IP and 6-k-PGF ${ }_{1 \alpha}$ production stimulated by various other nucleotides (Table I). After a 10-min exposure to nucleotide concentrations of $100 \mu \mathrm{M}$, ATP and ADP both produced significant elevations of total IP and 6-k-PGF ${ }_{1 \alpha}$, while adenosine and AMP had little or no effect. These data suggest that in retinal endothelial cells, ADP and ATP stimulate IP and $6-\mathrm{k}^{-} \mathrm{PGF}_{1 \alpha}$ formation action 
TABLE 1 .

The effect of various agonists on total inositol phosphates and 6-k-PGF ${ }_{1 \alpha}$ accumulation

\begin{tabular}{lcc} 
& \multicolumn{2}{c}{ Percent of control } \\
& IP & $6-k-P G F_{1 \alpha}$ \\
\hline Control & $100 \pm 7$ & $100 \pm 6$ \\
Adenosine & $91 \pm 3$ & $178 \pm 15$ \\
AMP & $104 \pm 4$ & $182 \pm 6$ \\
ADP & $392 \pm 4$ & $205 \pm 2$ \\
ATP & $535 \pm 3$ & $339 \pm 3$ \\
GTP & $242 \pm 5$ & $166 \pm 12$ \\
UTP & $160 \pm 5$ & $113 \pm 11$ \\
CTP & $143 \pm 2$ & $197 \pm 2$ \\
Bradykinin & $244 \pm 5$ & $180 \pm 13$ \\
Ca ${ }^{2+}$ ionophore A23187 & $99 \pm 4$ & $466 \pm 6$ \\
\hline
\end{tabular}

Inositol phosphates (IP) and 6-k-PGF ${ }_{1 \alpha}$ levels were measured 10 min after the addition of each agonist at a concentration of $100 \mu \mathrm{M}$, except for calcium ionophore which was $10 \mu \mathrm{M}$. Values are the mean of three determinations \pm S.E.M.

through $\mathrm{P}_{2}$ receptors. Nucleotides other than ATP also produced some stimulation of IP as well as prostacyclin, but all to a lesser degree than ATP and ADP. with decreasing efficacy GTP $>$ UTP $>$ CTP.

Bradykinin, a peptide with vasoactive properties, was tested for its capacity to stimulate IP and 6-k$\mathrm{PGF}_{1 x}$ formation in retinal endothelium. Bradykinin $(100 \mu \mathrm{M})$, after a 10-min exposure, stimulated IP formation to $244 \%$ of control. while $6-\mathrm{k}-\mathrm{PGF}_{1 \alpha}$ formation was $188 \%$ of control (Table I). The calcium ionophore A23187, at a concentration of $10 \mu \mathrm{M}$. also stimulated $6-\mathrm{k}-\mathrm{PGF}_{1 \alpha}$ formation to $466 \%$ of control, but induced no inositol phosphate production. consistent with the fact that phospholipase $A_{2}$, but not phospholipase $C$, is a calcium sensitive enzyme.

\section{Discussion}

We found that ATP and ADP, but not AMP or adenosine, induce rapid formation of prostacyclin and inositol phosphates in retinal microvascular endothelial cells. This pattern together with the weaker agonist responses to GTP, UTP, and CTP suggest mediation through $\mathrm{P}_{2}$ purinergic receptors on these cells. This receptor subtype has been defined in other types of endothelial cells on the basis of a similar pattern of relative potencies for the various adenine nucleotides (Burnstock, Cusack and Meldrum, 1985; Martin et al., 1985). Our data in retinal microvascular endothelium are consistent with recent reports that ATP and ADP stimulate phospholipid turnover and prostacyclin formation in aortic endothelium (Boeynaems and Galand, 1983: Needham et al., 1987; Pirotton et al.. 1987), and in bovine adrenal microvascular endothelium (Forsberg et al., 1987). In these cells, responses elicited by adenine nucleotides had the same agonist specificity as those we found in the retinal endothelium, suggesting they all derive from the activation of $\mathrm{P}_{2}$ purinergic receptors.

Although it is likely that the metabolic response to ATP in retinal endothelial cells involve $P_{2}$ receptors, it is not clear whether prostacyclin formation and PI lipid turnover are mediated through separate biochemical pathways or are sequential steps in a single pathway initiated by nucleotide receptor/ligand interaction. Several lines of evidence favour the latter hypothesis. Receptor-linked hydrolysis of plasma membrane PI lipids to inositol phosphates is now well established as a second messenger system (Michell, 1975). The initial response is the hydrolysis of phosphoinositol diphosphate $\left(\mathrm{PIP}_{2}\right)$ by phospholipase $\mathrm{C}$, producing $\mathrm{IP}_{3^{*}} \mathrm{IP}_{3}$ then stimulates release of $\mathrm{Ca}^{2+}$ from intracellular stores, resulting in an increase in the concentration of intracellular free $\mathrm{Ca}^{2+}$ (Berridge. 1984; Hokin, 1985). In virtually all systems in which it has been studied, stimulation of PI lipid turnover produces an elevation of intracellular $\mathrm{Ca}^{2+}$. ATP. specifically, stimulates this response along with $\mathrm{IP}_{3}$ production in bovine aortic endothelial cells (Pirotton et al., 1987). An elevation of intracellular free $\mathrm{Ca}^{2+}$ concentration also activates phospholipase $A_{z}$ in bovine endothelial cells, which in turn liberates arachidonic acid from membrane phospholipids (Lapetina, Billah and Cuatrecasas, 1981; Seld, MacNeil and Tomlinson, 1983). This step appears to be rate limiting in the formation of prostacyclin (Feinstein and Shaafi, 1983). The ability of $\mathrm{Ca}^{2+}$ to activate phospholipase $A_{2}$ in bovine aortic endothelium is supported by the evidence that the calcium ionophore A23187, which directly elevates cytosolic $\mathrm{Ca}^{2+}$ by allowing influx of intracellular calcium, stimulates formation of prostacyclin (Davies, 1981). This was also demonstrated in bovine retinal endothelium (Table I). Thus, a plausible sequence of events on stimulation of retinal endothelium by ATP is the initial hydrolysis of membrane $\mathrm{PIP}_{2}$ with formation of $\mathrm{IP}_{3}$, which in turn elevates intracellular $\mathrm{Ca}^{2+}$, activating phospholipase $A_{2}$. This enzyme liberates arachidonic acid from which prostacyclin is then produced.

Our results lend support to this scheme. The time course of ATP-stimulated production of $\mathrm{IP}_{3}$ in bovine retinal endothelial cells, very closely paralleled that of initial early 6-k-PGF ${ }_{1 \alpha}$ formation. Both $\mathrm{IP}_{3}$ and 6-k$\mathrm{PGF}_{1 x}$ began to rise by 10 sec, making it possible that an $\mathrm{IP}_{3}$-generated rise in intracellular $\mathrm{Ca}^{2+}$ could be responsible for prostacyclin formation. However, prostacyclin levels continued to increase after $\mathrm{IP}_{3}$ levels declined. This might be explained by a later influence of ATP on intracellular calcium mediated through a slower, sustained influx of extracellular calcium across the plasma membrane. Such an effect of ATP has been demonstrated in bovine aortic endothelial cells and in ascites tumor cells and is possible in retinal endothelium, although this has not yet heen specifically examined (Dubyak and DeYoung, 1985 ; Pirotton et al., 1987). Moreover. metabolism of PI lipids results in 
the formation of diacylglycerol which. when degraded by diacylglycerol lipase, is also a source of arachidonic acid (Berridge. 1984; Hokin, 1985). Even though IP formation is short-lived, $\mathrm{IP}_{1}$ levels continue to rise for $20 \mathrm{~min}$ where they are stable until $60 \mathrm{~min}$ (Fig. 4). The rising levels are primarily produced by ongoing $\mathrm{IP}_{1}$ formation, while the plateau may reflect inhibition of its degradation by IP -phosphatase, due to the lithium chloride present in the medium. The total accumulation of $\mathrm{IP}_{1}$ is greater than can be readily accounted for by sequential breakdown of $\mathrm{IP}_{3}$ and IP and suggests delayed hydrolysis of PI and possibly PIP, with continued availability of diacylglycerol for arachidonic acid and prostacyclin synthesis (Bell et al.. 1979).

The dose-response curves for ATP-stimulated total IP and $6-\mathrm{k}-\mathrm{PGF}_{1 x}$ production in retinal endothelial cells were not identical. Concentrations of ATP between $0 \cdot 1 \mu \mathrm{M}$ and $10 \mu \mathrm{M}$ ATP increase stimulation of both IP and 6-k-PGF ${ }_{1 x}$. However, between 10 and $1000 \mu \mathrm{M}$ ATP, the production of IP reached a plateau, while that of $6-\mathrm{k}-\mathrm{PGF}_{1 \alpha}$ continued to increase. Thus, although some prostacyclin formation could result from $\mathrm{IP}_{3}$-mediated elevation of intracellular $\mathrm{Ca}^{2+}$, other mechanisms are required to account for the progressive increase in $6-\mathrm{k}-\mathrm{PGF}_{1 x}$ formation at higher ATP concentrations. Again, an additional influence of ATP upon intracellular $\mathrm{Ca}^{2+}$ levels, with a different dose-response curve from that for IP formation, could be one such mechanism. With respect to these dose-response curves, our data differs somewhat from that obtained with adrenal microvascular endothelium. where IP and 6-k-PGF ${ }_{1 x}$ production were similar between concentrations of $10 \mu \mathrm{M}$ and $1000 \mu \mathrm{M}$ ATP (Forsberg et al., 1987). The time courses of $\mathrm{IP}_{3}$ and $6-\mathrm{k}-\mathrm{PGF}_{1 x}$ formation were also similar to one another, as they were with the retinal endothelium. Time courses and dose-response curves of IP and 6-k$\mathrm{PGF}_{1 \alpha}$ formation in aortic endothelium were also quite similar to one another (Pirotton et al., 1987). Reasons for the differences in dose responses between retinal endothelium and other endothelial cell types is not apparent from these experiments, but may lie in receptor subtype differences or in their transduction mechanisms. Taken together, these results support the hypothesis that sequential effects of adenine nucleotide stimulated PI hydrolysis lead to prostacyclin formation in vascular endothelium.

The findings that ATP and ADP interaction with receptors on retinal microvascular endothelium is linked to membrane PI lipid hydrolysis and prostacyclin formation, suggest several ways this could influence retinal vascular autoregulation in vivo. First, prostacyclin itself is known to be a potent vasodilator (Wiksler, Ley and Jaffe, 1978) and its release by retinal endothelium could cause vasodilation of retinal blood vessels. Second, the stimulation of PI turnover in retinal endothelium may be linked to the formation of endothelium-derived relaxation factor. This factor. recently identified as nitric oxide (Palmer. Ferridge and Moncada, 1987), is secreted by large vessel endothelium in response to various stimuli and is a potent vasodilator. The production of relaxing factor by porcine aortic endothelium in culture (Martin et al. 1985 ) is stimulated by the same adenine nucleotide agonists and at similar doses as prostacyclin formation in these cells (Needham et al., 1987), and IP production in bovine aortic endothelial cells (Pirotton et al., 1987). Moreover, bradykinin stimulates formation of endothelial relaxing factor (Cochs et al.. 1985) and prostacyclin and IP production (Derian and Moskowitz, 1986) in bovine aortic endothelial cells. Since ATP and bradykinin stimulate IP and prostacyclin formation in retinal endothelium, relaxing factor may be produced by these cells as well, and influence retinal autoregulation.

It is likely that the concentration of ATP present in the vicinity of retinal endothelial $P_{2}$ purinergic receptors is high enough to trigger the responses we demonstrated in vitro. While under normal conditions, levels of ATP in the blood are quite low, marked increases occur in many vascular beds under hypoxic conditions (Forrester and Lind, 1969; Berne, Rubio and Curnish, 1974). Vascular cells release intracellular stores of ATP after hypoxic insults, with concentrations reaching levels more than sufficient to stimulate $\mathrm{P}_{2}$ endothelial receptors (Pearson and Gordon, 1979). ATP is released from brain slices and synaptosomes in response to depolarizing stimuli and may be released after retinal depolarization as well, with potential availability to vascular receptors (Stone, 1981). Platelet aggregation is also an event that results in the release of high concentrations of ATP and ADP which could interact with endothelial receptor (Mills, Robb and Roberts, 1968).

There is convincing evidence of endothelial cell dysfunction in diabetic retinopathy (Porta et al., 1981). However, the precise metabolic alterations have been difficult to determine. Microvascular occlusion ultimately results, but there is evidence that impaired autoregulation of retinal vessels precedes morphologic evidence of retinal vasculopathy (Small, Stefánsson and Hatchell, 1987).

The pathology of the neuropathy of diabetes has been linked to alterations of sorbitol and myo-inositol metabolism secondary to hyperglycemia, with decreased myo-inositol content of peripheral nerve (Gillon and Hawthorne, 1983; Greene and Lattimer, 1985). Reduced cellular myo-inositol in nerve manifests itself in abnormal phospholipid metabolism (Bell. Peterson and Eichberg, 1982; Simmons, Winegrad and Martin, 1982).

High concentrations of glucose and sorbitol with decreased myo-inositol levels have also been found in the retina in diabetes (MacGregor et al., 1986). As in peripheral nerve, decreased myo-inositol levels in retina could affect PI lipid metabolism. If PI turnover in part mediates retinal autoregulation, its alteration 
in diabetes could result in decreased production of vascular prostacyclin and relaxing factor, with inappropriate vasoconstriction and pathologic changes in vascular tone. Thus, altered metabolism of PI lipids may underlie the basic pathophysiology of diabetic retinopathy.

We have found that ATP/ADP, probably acting through $\mathrm{P}_{2}$ purinergic receptors, and bradykinin stimulate the formation of prostacyclin and inositol phosphates in retinal microvascular endothelial cells in culture. We suggest that retinal autoregulation may be mediated, in part, through these biochemical pathways.

\section{References}

Bell, M. E., Peterson, R. G. and Eichberg. J. (1982). Metabolism of phospholipids in peripheral nerve from rats with chronic streptozotocin-induced diabetes: Increased turnover of phosphatidylinositol-4.5-triphosphate. I. Neurochem. 39. 192-200.

Bell, R. L., Kennerly, D. A., Stanford, N. and Majerus, P. W. (1979). Diglyceride lipase A: A pathway for arachidonate release from human platelets. Proc. Natl. Acad. Sci. U.S.A. 76, 3238-41.

Berne, R. M., Rubio, R, and Curnish, R. R. (1974). Release of adenosine from ischemic brain: Effect on cerebral vascular resistance and incorporation into cerebral adenine nucleotides. Circ. Res. 35, 262-71.

Berridge, M. J. (1984). Inositol triphosphate and diacylglycerol as second messengers. Biochem J. 220, 345-60.

Berridge, M. J., Dawson, R. M. C., Downes, C. P., Heslop, J. P. and Irvine. R. G. (1983). Changes in the levels of inositol phosphates after agonist-dependent hydrolysis of membrane phosphoinositides Biochem. J. 212, 47382.

Boeynaems, J. M. and Galand, N. (1984). Stimulation of vascular prostacyclin synthesis by extracellular ADP and ATP. Biochem Biophys. Res. Commun. 112, 290-6.

Burnstock, G., Cusack, N. J. and Meldrum L. A. (1985). Studies on the stereoselectivity of the $\mathrm{P}_{2}$-purinoreceptor on the guinea-pig vas deferens. $B r$. J. Pharmacol. 84 , $431-4$

Chand. N. and Altura, B. M. (1981). Acetylcholine and bradykinin relax isolated pulmonary arteries by acting on endothelial cells: role in lung vascular disease. Science 213, 1376-9.

Cocks, T. M., Angus, J. A., Campbell, J. H. and Campbell G. R. (1985). Release and properties of endotheliumderived relaxing factor (EDRF) from endothelial cells in culture. 1. Cell Physiol. 123, 310-20.

Cunha-Vaz., J. G. (1976). The blood-retinal barriers. Doc. Ophthalmol. 41, 287-327.

Davies, P.F. (1981). Microcarrier culture of vascular endothelial cells on solid plastic beads. Exp. Cell Res. $134,367-76$

Derian. C. K. and Moskowitz. M. A. (1986). Polyphosphoinositide hydrolysis in endothelial cells and carotid artery segments. J. Biol Chem. 261, 3831-7.

Dollery, C. I., Hill, D. W. and Hodge, J. V. (1963). The response of normal retinal blood vessels to angiotensin and noradrenaline. J. Physiol. 165, 500-7.

Dubyak. G. R. and DeYoung. M. B. (1985). Intracellular $\mathrm{Ca}^{2+}$ mobilization activated by extracellular ATP in Erlich ascites tumor cells. J. Biol. Chem. 260, 10653-61.

Feinstein, M. I. and Shaafi, R. I. (1983). Role of calcium in arachidonic acid metabolism and in the action of arachidonic acid-derived metabolites. In Calcium and Cell Function, Vol IV. (Ed. Cheung, W. J.) Pp. 337-76. Academic Press: London.

Forrester, T. and Lind, A. R. (1969). Identification of adenosine triphosphate in human plasma and the concentration in the venous effluent of forearm muscles before, during, and after sustained contractions. J. Physiol. 204, 347-64.

Forsberg, E. J., Feuerstein, G., Shohanic, E. and Pollard, H. B. (1987). Adenosine triphosphate stimulates inositol phospholipid metabolism and prostacyclin formation in adrenal medullary endothelial cells by means of $\mathrm{P}_{2}$ purinergic receptors. Proc. Natl. Acad. Sci. U.S.A. 84. $5630-4$.

Furchgott. R. F. and Zawadzki. J. V. (1980). The obligatory role of endothelial cells in the relaxation of arterial smooth muscle by acetylcholine. Nature 288, 373-6.

Gillon. K. R. W. and Hawthorne, J. N. (1983). Transport of myo-inositol into endoneurial preparations of sciatic nerve from normal and streptozotocin-diabetic rats. Biochem. J. 210, 775-81.

Greene, D. A. and Lattimer, S. A. (1985). Altered nerve myo-inositol metabolism in experimental diabetes and its relationship to nerve function. In Inositol and Phosphoinositides Metabolism and Biological Regulation. (Eds Bleasdale. J. E., Eichberg, J. and Hauser, G.) Pp. 563-82. Humana Press: Clifton, NJ.

Hokin, L. E. (1985). Receptors and phosphoinositide-generated second messengers. Annu. Rev. Biochem. 54 , 205-35.

Isacopoulos. M. (1977). Regulation of retinal blood flow. In Scientific Foundations of Ophthalmology. (Eds Perkin E. S. and Hill D. W.) Pp. 44-9. William Heinemann Medical Books: London.

Jaffe, E. A., Hoyer, L. W. and Nachman R. L. (1973). Synthesis of antihemophilic factor by cultured human endothelial cells. J. Clin. Invest. 52, 2757-64.

Lapetina, E. G. Billah, M. M. and Cuatrecasas, P. (1981). The phosphatidylinositol cycle and the regulation of arachidonic acid production. Nature 292, 367-9.

MacGregor, L. C., Rosecan, L. R., Laties, A. M. and Matschinsky, F. M. (1986). Altered retinal metabolism in diabetes. I. Biol. Chem. 261, 4046-51.

Martin. W., Cusack. N. J., Carleton. J. S. and Gordon, J. L. (1985). Specificity of $\mathrm{P}_{4}$-purinoreceptor that mediates endothelium-dependent relaxation of the pig aorta. Eur. I. Pharmacol. 108, 295-9.

Michell, R. A. (1975). Inositol phospholipids and cell surface receptor function. Biochim. Biophys. Acta 415, 81-147.

Mills, D. C. B., Robb, I. A. and Roberts, G. C. K. (1968). The release of nucleotides, 5-hydroxytryptamine and enzymes from human blood platelets during aggregation. J. Physiol. (Lond.) 195. 715-29.

Needham, L., Cusack, N. J., Pearson, J. D. and Gordon, J. L. (1987). Characteristics of the $P_{2}$-purinoreceptor that mediates prostacyclin production by pig aortic endothelial cells. Eur. J. Pharmacol. 134, 199-209.

Palmer, R. M. J., Ferridge, A. G. and Moncada, S. (1987). Nitric oxide release accounts for the biological activity of endothelium-derived relaxing factor. Nature 327 . $524-6$.

Pearson. J. D. and Gordon J. L. (1979). Vascular endothelial and smooth muscle cells in culture selectively release adenine nucleotides. Nature 281, 384-6.

Pirotton, S., Raspe, E., Demolle, D., Erneux. C. and Boeynaems, J. (1987). Involvement of inositol 1.4.5 triphosphate and calcium in the action of adenine nucleotides on aortic endothelial cells. J. Biol. Chem. 262, 17461-6. 
Porta, M. Townsend, C.. Clover, G. M. et al. (1981). Evidence for endothelial cell damage in early diabetic retinopathy. Diabetologia 20, 597-601.

Rockwood, E. J.. Fantes, F., Davis, E. B. and Anderson D. R. (1987). The response of retinal vasculature to angiotensin. Invest. Ophthalmol. Vis. Sci. 28, 676-82.

Seld, J. M. MacNeil. S. and Tomlinson, S. (1983). Calcium, calmodulin, and the production of prostacyclin by cultured vascular endothelial cells. Biosci. Rep. 3 , $1007-15$.

Simmons, D. A. Winegrad, A. I. and Martin, D. B. (1982). Significance of tissue myo-inositol in metabolic regulation of nerve. Science 217, 848-51.

Small, K. W., Stefánsson E. and Hatchell, D. L. (1987).
Retinal blood flow in normal and diabetic dogs. Invest. Ophthalmol Vis. Sci. 28, 672-5.

Stone, T. W. (1981). Physiological roles for adenosine and adenosine 5'triphosphate in the nervous system. Neurosci. 6, 523-55.

Voyta, J. C.. Via, D. P.. Butterfield, C. E. and Zetter, B. R. (1984). Identification and isolation of endothelial cells based on their increased uptake of acetylated-low density lipoprotein. J. Cell. Biol. 99. 2034-40.

Wiksler, B. B., Ley. C. W. and Jaffe, E. A. (1978). Stimulation of endothelial cell prostacyclin production by thrombin. trypsin, and ionophore A23187. J. Clin. Invest. 62. 923-30. 